abscesses occurred in $17(13 \%)$. Primary or secondary excision was used in 74. The initial surgical procedure was aspiration in 71. Staphylococcus, Streptococcus and Proteus were the predominant microorganisms. Cephalosporins were used only recently and penicillin and chloramphenicol were the antibiotics used in earlier cases. Mortality was $15 \%$ overall, but $6 \%$ in the last 5 years and 0 in the last 3 years. Mortality in infants was $50 \%$ (Tekkok IH, Erbengi A. Management of brain abscess in children: review of 130 cases over a period of 21 years. Child's Nerv Sys Oct 1992; $\underline{8}: 411$ 416). (Correspondence: I.H. Tekkok, M.D., Department of Neurosurgery, Hacettepe University School of Medicine, Sihhiye, Ankara 06100, Turkey.)

COMMENT. The medical cure of a brain stem abscess and serial brainstem auditory evoked potentials are reported from the Department of Pediatrics, Chang Gung Memorial Hospital, 199 Tung-Hua N. Road, Taipei, Taiwan, Republic of China (Wang HS et al. Dev Med Child Neurol Oct 1992; 34:911-915). A 9 year-old girl with tetralogy of Fallot was cured after 6 weeks of parenteral antibiotic therapy, without surgical intervention. The initial brainstem auditory evoked potential showed poor demonstration of right waves IV and V, and delay of right wave III and left wave V. Serial follow-up showed improving latencies and wave forms but persistent abnormalities on the right side. The patient presented with a right-sided ptosis, abducens palsy and peripheral facial palsy and left hemiparesis. CT showed a hypodense lesion in the brain stem. Vancomycin and chloramphenicol were the antibiotics used in treatment.

\title{
CT IN ACUTE MENINGITIS
}

The role of CT in the acute management of bacterial meningitis in 30 children was evaluated at the Department of Pediatrics, St. Mary's Hospital Medical School, London, England. Cranial CT was normal in 10 patients, 5 with raised intracranial pressure, 1 with focal neurological signs and 1 with generalized convulsions. Significant CT abnormalities were detected in 10 patients, 4 with subdural effusion, 4 with cerebral infarct, 1 hydrocephalus, and 1 empyema. CT identified a surgical abnormality in 2 patients with progressive focal neurological signs (Heyderman RS, Robb SA, Kendall BE, Levin M. Does computed tomography have a role in the evaluation of complicated acute bacterial meningitis in childhood? Dev Med and Child Neurol Oct 1992; 34:870-875). (Correspondence: Dr. R.S. Heyderman, Department of Pediatrics, Queen Elizabeth the Queen Mother Wing, St. Mary's Hospital Medical School, South Wharf Road, London W2 1NY.)

COMMENT. This study shows that the role of CT in the management of acute bacterial meningitis is limited, but may be valuable in those with progressive neurological signs for whom neurosurgical intervention may be necessary.

The long-term follow-up of acute bacterial meningitis in 74 children is reported from Taiyuan City, China (Yi LY, Qiong YS. 
Pediatr Neurol Sept/Oct 1992; $\underline{8}: 404$ (abstract). Neurologic sequelae occurred in $33.8 \%$ of survivors: $54 \%$ had mental retardation, $50 \%$ epilepsy, $33 \%$ paralysis, $16 \%$ sensorineural hearing loss and $4 \%$ blindness. Other abnormalities included growth retardation, hyperactivity and irritability. Dexamethasone reduced the incidence of hearing loss.

Cranial CT conducted in 199 children with tuberculous meningitis in Cape Town, Republic of South Africa, showed basal ganglia infarcts in $30 \%$, which corresponded with hemiplegia (Schoeman JF et al. Pediatr Neurol Sept/Oct 1992; $\underline{8}: 355$ (abstract).

\section{SEIZURE DISORDERS}

\section{BENIGN NEONATAL SLEEP MYOCLONUS}

Benign neonatal sleep myoclonus was diagnosed in 10 infants at the Children's Hospital, Winnipeg, Manitoba. The neonates were referred for assessment of seizures. The myoclonus increased with gentle restraint and in 2 patients it worsened in spite of anticonvulsant therapy. None of the clinical events was associated with EEG seizure phenomena. All infants were neurodevelopmentally normal between the ages of 4 months and 5 years. The myoclonus remitted by age 6 months in all but 2 infants (Daoust-Roy J, Seshia SS. Benign neonatal sleep myoclonus. A differential diagnosis of neonatal seizures. AJDC Oct 1992; 146:1236-1241). (Reprints: Dr. Seshia, Section of Pediatric Neurosciences, Children's Hospital, AE208, 840 Sherbrook St., Winnipeg, Manitoba, Canada R3A 1S1.)

COMMENT. Benign neonatal sleep myoclonus has the following characteristics: 1) neonatal onset, 2) myoclonic jerks only during sleep, 3) abrupt and consistent cessation with arousal, 4) absence of EEG seizure activity and 5) good prognosis. This entity must be distinguished from benign familial neonatal seizures and anticonvulsants should be withheld. The condition should also be differentiated from neonatal hyperekplexia which is characterized by massive jerks in response to sudden tactile and acoustic stimuli and long lasting myoclonic jerks closely resembling epileptic seizures (Pascotto A, Coppola G. Neonatal hyperekplexia: a case report. Epilepsia Sept/Oct $1992 ; \underline{33}: 817-820)$.

Benign myoclonic epilepsy of early childhood reported in 20 children from Riyadh, Saudi Arabia (Gascon GG et al. Pediatr Neurol Sept/Oct $1992 ; \underline{8}: 348$ (abstract)) was considered a phenotype differing only in the age of onset, but sharing the same genotype as benign infantile myoclonic epilepsy and juvenile myoclonic epilepsy.

Benign myoclonus of early infancy was reported in 6 cases from Milan, Italy (Nardoccin et al. Pediatr Neurol Sept/Oct 1992; $\underline{8}: 404$ 